\title{
O Pianista Colaborador: Um Estudo no Contexto da UDESC, em Florianópolis
}

The collaborator pianist: a study in the context of UDESC in Florianópolis

Cinthia Ruivo Silva', Guilherme Sauerbronn Barros² 


\section{Resumo}

Esse artigo tem como objeto de estudo o pianista colaborador. $O$ trabalho está dividido em três partes. A primeira tem caráter histórico e descreve o pianista colaborador. A segunda é uma breve análise curricular do bacharelado em piano da Universidade Estadual de Santa Catarina, a fim de identificar se há matérias que direcionem os alunos para prática colaborativa e a terceira é o relato de uma oficina de piano colaborativo realizada naquela instituição. Esse trabalho teve como objetivo aprimorar o desempenho de pianistas que realizam ou desejam realizar a prática da colaboração. A obtenção dos dados dessa pesquisa foi feita através da gravação das aulas em vídeo, de um questionário semi-estruturado e de uma entrevista. A oficina demonstrou, entre outras coisas que $o$ desenvolvimento da leitura à primeira vista é de extrema importância para a prática colaborativa e que, através de um estudo direcionado durante os anos de formação, essa dificuldade pode vir a ser superada.

Palavras-Chave: pianista colaborador; leitura à primeira vista; ensaio;

\section{Abstract}

This article has as its object of study collaborator pianist. The work is divided into three parts. The first has historic character and describes the collaborative pianist. The second is a brief analysis of the curricular degree in piano from the State University of Santa Catarina, in order to identify if there are matters that direct students to collaborative practice and the third is the report of a workshop held in that institution collaborative piano. This study aimed to improve the performance of pianists who perform or want to perform the practice of collaboration. The data collection of this research was done by recording the video lessons, a semi-structured questionnaire and an interview. The workshop demonstrated, among other things the development of sight-reading is very important for collaborative practice and, through a directed study during the formative years, this difficulty might be overcome.

Keywords: collaborative pianist; sight reading, Rehearsal;

ISSN: 1808-3129

1 Mestranda em Música - Prática interpretativas - piano - na Universidade 


\section{Introdução}

O pianista colaborador, segundo Mundin (2009), é aquele que desempenha função de 'ensaiador' para preparação de solistas para performance, realizando ou executando reduções de orquestra, juntamente com o professor de canto, de instrumento ou com o maestro e, se necessário, até mesmo substituindo-os. Já o pianista colaborador, é definido como o instrumentista virtuose que apurou sua técnica pianística através do estudo do instrumento solo e que desenvolveu habilidades de interação com outros solistas, adquiridas a partir da vivência cotidiana da música de câmara e observância de técnicas e particularidades de outros instrumentos. Costa (2011) utiliza um termo mais abrangente para esse profissional: pianista colaborador. Katz (2009) diz que ao acompanhar outro instrumentista, estamos colaborando com a execução musical. Sendo assim, baseado em Katz (2009), Mundin (2009) e Costa (2011) utilizaremos o termo pianista colaborador e colaboração para definir o papel desempenhado pelo pianista.

Ao longo dos meus estudos musicais, tive a oportunidade de acompanhar diversos músicos, em formações variadas, tanto em recitais, provas, master classes como em aulas particulares. Durante esse processo, percebi lacunas que dificultavam meu trabalho como pianista colaboradora, as quais procurei preencher a partir da própria prática. Após observar alunos de alguns cursos de graduação no Paraná e em Santa Catarina, percebi que, assim como eu, aqueles pianistas não haviam desenvolvido o conhecimento sólido para exercer a prática colaborativa. Como hipótese, acreditamos que a preparação dos alunos de piano para a atividade colaborativa durante os anos de aprendizado acadêmico aumentará suas possibilidades de atuação profissional, e ao mesmo tempo evitará que o aprendizado informal ${ }^{3}$ seja o único meio de formação do pianista colaborador.

Para a realização dessa pesquisa montamos uma oficina de piano colaborativo da qual participaram cinco alunos de piano do curso de graduação em Música da Universidade Estadual de Santa Catarina (UDESC). A presente pesquisa teve os seguintes objetivos:

- Discutir o desenvolvimento das habilidades necessárias à prática do piano colaborativo;

- Usar o estágio docente como laboratório para o desenvolvimento de habilidades relacionadas à prática do piano colaborativo entre alunos do bacharelado em piano da UDESC, bem como fonte primária de informações sobre suas expectativas profissionais e musicais, e,

- Investigar se a atividade de pianista colaborador é compatível com as expectativas profissionais e artísticas dos alunos de bacharelado em piano da UDESC.

\footnotetext{
${ }^{3}$ Segundo Mardegan (2011), existem 7 meios de aprendizagem informal: nas atividades diárias, nas interações sociais, por meio de liderança, autodirigida, reflexão, observação e por meio de erros. Esse tipo de aprendizado caracteriza-se pelo conhecimento adquirido dia a dia através das atividades desem-
}

penhadas pelos pianistas durante a prática colaborativa. A desvantagem deste aprendizado são os "vícios" que os pianistas podem desenvolver, tornando-se prejudiciais à performance do intérprete. 


\section{O Pianista Colaborador}

A atividade de colaboração ao piano é uma área de estudos que vem atraindo o interesse de grande número de pesquisadores. Termo consagrado no Brasil nas últimas décadas do século $\mathrm{XX}$, o pianista colaborador agrega as funções de pianista correpetidor, acompanhador e camerista (MUNIZ, 2010). Devido à natureza das habilidades que domina, existe uma grande demanda por esse tipo de músico no mercado da música erudita, tanto no contexto global como no caso particular do Brasil. Atualmente o pianista colaborador divide o espaço com o pianista solista em diversas instituições de ensino superior, não apenas como executante (técnico), mas como docente de disciplinas ligadas à sua atividade. É importante ressaltar que o pianista colaborador não vem necessariamente ocupar o lugar do solista mas, como reconhece Unglaub (2006), na sociedade em que vivemos o campo de atuação para o solista tem se tornado cada vez mais restrito, ao passo que a colaboração pianística tem se destacado e sido buscada pelos pianistas.

Atualmente existem profissionais no meio acadêmico que trabalham especificamente com o piano colaborativo e, em alguns casos, na formação dos alunos para esta atividade. Segundo Montenegro (2013), o pianista colaborador passou a ser altamente requisitado nas instituições de ensino musical, tais como escolas e institutos de educação, mas são as universidades que têm demonstrado mais interesse por este profissional nos últimos anos. Em uma pesquisa realizada sobre os editais de concursos públicos por Montenegro $(2013)^{4}$, foram detectadas seleções para a contratação desse profissional na Universidade Federal de Santa Maria (UFSM), Universidade Federal de Pernambuco (UFPE), Universidade Federal de Uberlândia (UFU), Instituto Federal de Educação Tecnológica de Goiás (IFG) e de Mato Grosso do Sul (IFMS), e Universidade Federal do Rio de Janeiro (UFRJ). O requisito mínimo para a realização desses concursos é a graduação em Música - bacharelado ou licenciatura, dependendo da instituição contratante ${ }^{5}$.

Para Katz (2009), as funções imediatas do trabalho do colaborador são: sincronização rítmica, alinhamento vertical e cuidado com o volume (funções comuns às do solista). Suas principais responsabilidades e habilidades são: o domínio técnico no instrumento; uma leitura à primeira vista desenvolvida; ler "ampliadamente" os sistemas da partitura, isto é, ler a parte do piano e a do solista ao mesmo tempo; ler grades orquestrais com a habilidade de transposição, quando necessário; ler cifras e improvisar; ter um conhecimento amplo do repertório e saber lidar com situações adversas que podem acontecer em ensaios e apresentações. Além disso, o colaborador deve estar atento às instruções e aos anseios do compositor, ao sentido do texto (em obras cantadas ou declamadas). Segundo ele, o conjunto perfeito e o equilíbrio

${ }^{4}$ Pesquisa realizada por Guilherme Farias de Castro Montenegro Universidade de Brasília -UnB-2013 - Dados levantados no site do PCI Concursos. Disponível em < http://www.pciconcursos.com.br> Acesso em 19 junho 2012.
${ }^{5}$ Analisando alguns editais mais recentes, verificamos que, na maior parte dos casos, a vaga não é para professor e sim para técnico na área colaborativa. Apenas a UNIRIO ofertou a vaga para a cadeira de professor, através do Edital No64/2012 (Área/Disciplina: Música/Recital - Exigência: Graduação em Música/Piano; Mestrado em Música/Piano ou áreas afins; Experiência profissional: três (3) anos em ensino de piano e experiência comprovada como camerista e co-repetidor). 
sonoro entre os músicos são essenciais e, o pilar central do sucesso na colaboração pianística é a respiração ${ }^{6}$. Para o pianista, cantar e respirar são atividades cruciais para o bom desempenho musical. Por ser um fator fisiológico, a respiração é um elemento central na atividade de cantores, mas sua importância não é necessariamente reconhecida por pianistas, que não dependem diretamente dela na execução instrumental.

"Se você não pode cantá-lo [um trecho musical], você não pode tocá-lo! Ao can-
tar, eu não quero dizer murmurando, sussurrando, ou balbuciando para evitar
constrangimento; Eu estou falando de realmente usar e aproveitar nossas próprias
vozes, e, como resultado, tirar energia da respiração ${ }^{7}$.(KATZ, 2009, p. 07)

Ao acompanhar cantores o pianista precisa ter a habilidade de transpor e saber identificar, através do ouvido, se determinado tom fica em uma região confortável para o cantor. É muito comum o surgimento de dúvidas em relação à tonalidade da partitura. Existem tonalidades específicas para as diversas vozes mas, a mudança aparentemente insignificante de meio tom acima ou abaixo pode fazer diferença no brilho de algumas notas ou até mesmo tornar as notas de passagem um pouco mais confortáveis para o cantor. (MUNDIN, 2009). Essa transposição é realizada de forma simples pelos cantores, pois eles seguem a leitura intervalar ou cantam de "ouvido". Para o pianista esse processo é bem mais complexo e envolve questões técnicas, anatômicas e racionais (matemáticas). Em relação ao texto poético, o pianista colaborador não precisa ser necessariamente fluente em línguas estrangeiras mas, é necessário que tenha um conhecimento básico da dicção das mesmas para que, durante o preparo musical dos cantores possa eventualmente corrigi-los. (ADLER, 1965). Neste sentido, é fundamental que a determinação dos acentos das frases musicais respeite, sempre que possível, os acentos fonéticos da língua que está sendo cantada. No acompanhamento de cordas, além do conhecimento da linguagem e da técnica dessa família de instrumentos, é necessário que o pianista perceba auditivamente as falhas de afinação. Nos instrumentos de sopro, assim como com os cantores, o cuidado com a respiração é de extrema importância; porém existem ainda os instrumentos transpositores como por exemplo o clarinete, que exige do colaborador desenvoltura na leitura na clave de dó. (KATZ, 2009, p.7-21).

De um ponto de vista pedagógico, tocar em conjunto deveria fazer parte da formação de todo instrumentista, mas, essa oportunidade nem sempre é bem aproveitada durante a formação do pianista e nos bacharelados acadêmicos a dedicação ao repertório solo tende a ser consideravelmente maior do que ao repertório de câmera. Quando realizamos a prática musical em conjunto, desenvolvemos o "ouvido simultâneo", que nos permite ouvir a nós mesmos e também o músico que estamos acompanhando. Sendo assim, como a necessidade do trabalho camerístico é fundamental durante os anos de aprendizado faremos uma breve análise no currículo do ${ }^{6}$ The primary building block of successful collaboration is surely the breath.
(KATZ, 2009, p. 07)
7 If you can't sing it, you can't play it! By singing, I do not mean murmuring, whispering, or mouthing words to avoid embarrassment; I am speaking of truly using and enjoying our own voices, and as a result, requiring fuel in the form of breaths.( KATZ, 2009) 
bacharelado em piano na UDESC para sabermos se esse trabalho é compatível com as necessidades do mercado de trabalho. É importante ressaltar que não é nosso objetivo avaliar o currículo da instituição mas apenas observar aspectos pontuais relacionado com a prática colaborativa

\section{O Bacharelado em Piano na UDESC}

A Universidade Estadual de Santa Catarina possui um centro de artes (CEART) que agrega os cursos de artes cênicas e visuais, moda e música. Em nossa pesquisa manteremos o foco apenas no curso de música, bacharelado em piano ${ }^{8}$. Ao observarmos a grade curricular do curso de piano notamos que o curso de música de câmara é oferecido até a 6a fase, o que possibilita aos alunos o acesso ao repertório camerístico mas, poucas são as matérias que habilitam o pianista a desenvolver de forma mais especializada a prática colaborativa. Cito como exemplo a matéria "leitura à primeira vista", fundamental para o pianista colaborador e que, no entanto, é oferecida como disciplina eletiva e não obrigatória. A maior parte dos alunos, principalmente os "calouros", não tem consciência da importância dessa prática na formação do pianista e acabam dando prioridade às outras matérias. Para o desenvolvimento dessa habilidade, segundo os pianistas Nahim Marun e Achille Picchi em entrevista realizada por Risarto (2008), é necessário que haja o estudo em paralelo dos seguintes conhecimentos musicais: técnica pianística e reflexos motores, para evitar erros de localização, execução mecânica e alternância de olhares entre mãos e partitura; harmonia e contraponto, para a realização da análise estrutural e textural da obra; conhecimento de repertório, que ajudará na identificação do estilo da obra. O direcionamento da leitura à primeira vista está relacionado à organização do trabalho de leitura e ao nível de conhecimento musical do pianista e/ou músico. Segundo o pianista colaborador Ricardo Ballestero em entrevista realizada por Risarto (2008) diz o seguinte sobre a leitura à primeira vista:

Acho que quanto mais eficiente uma leitura à primeira vista for, mais ela revela as qualidades do intérprete. Não é que você tenha que ler tudo que lá está, mas como você articula o seu conhecimento e como você associa esse conhecimento que está por trás, naquele momento: conhecimento do seu corpo, da técnica pianística, conhecimento de harmonia, de contraponto, conhecimento do que é novo ou não naquele estilo - então, são muitas coisas (RISARTO, 2008, entrev. 20, perg. 2).

É importante ressaltar aqui que, a solução para os alunos não é apenas uma questão de ofertar disciplinas, mas pensá-las em conjunto, direcionando para a formação do pianista colaborador. Segundo consta no site da UDESC ${ }^{9}$, o curso de música dessa instituição visa à formação de instrumentistas, preparando profissionais com embasamento artístico, técnico e científico necessários à atividade do músico.

80 curso de Música foi criado a partir da reformulação curricular ocorrida em 1993 no curso de Educação Artística (Resolução 031/93 - CONSUNI Alterada pelas Resoluções 041/94 - CONSUNI e 015/96 - CONSEPE), mas o Bacharelado em Música da UDESC só foi instituído no ano seguinte. Conforme informação disponível em http://www.secon.udesc.br/consuni/resol/1993/031-93-cni.pdf. Acesso em 28/05/2014
9 Conforme a informação disponivel em http://www.ceart.udesc.br/musical. Acesso em 28/05/2014. 
No entanto, quando os alunos ingressam na Universidade, buscam o ideal de "pianista" sem, na maior parte das vezes, ter noção de quais habilidades serão importantes para o seu desenvolvimento e sucesso no mercado de trabalho após sua formação. (UTRABO, 2012).

Em seu trabalho de conclusão de curso, Utrabo (2012) analisa as perspectivas dos alunos ao entrarem em uma faculdade de música. Ao serem questionados sobre a escolha pelo curso de bacharelado em piano 36,6\% (em números exatos, 11 dos 30 entrevistados) disseram estar em busca de "aperfeiçoamento técnico e aprofundar conhecimentos musicais". Apenas 3,3\% (1 aluno) disseram querer ser "concertista de câmara". Quanto à carreira de solista, apenas 10\% a almejavam quando ingressavam no Curso. Um dos egressos entrevistados por Utrabo (2012), ao ser questionado sobre suas perspectivas profissionais, respondeu o seguinte: “... acho que a universidade deveria mostrar de forma mais clara qual a área de atuação de cada profissional que ela forma para poder orientar os futuros candidatos." (UTRABO, 2012 p.29)

Quando os egressos foram questionados sobre a contribuição das disciplinas para o preparo profissional "a maioria não sentiu-se preparada para o mercado de trabalho" e que se pudessem, acrescentariam disciplinas que os preparassem mais efetivamente para as demandas profissionais. Dos egressos por ela entrevistados, 40\% aumentariam a carga horária de música de câmara. (UTRABO, 2012). Segundo o enfoque defendido no presente estudo, o trabalho com outros instrumentistas ajuda o pianista a conhecer a capacidade e o equilíbrio sonoro do seu instrumento, contribuindo na construção musical em conjunto. O conhecido pianista, compositor e pedagogo Heitor Alimonda, em entrevista realizada por Barros (1998) relata que:

O relacionamento com outros músicos, de diferentes instrumentos, obrigou-o a conhecer outros usos do seu próprio instrumento. Tocando com um violino, por exemplo, o piano é obrigado a sustentar os graves a maior parte do tempo, a atingir uma intensidade relativa àquela que o outro instrumento pode alcançar, e assim por diante. Com um violoncelo, a história é outra. Com um fagote, ainda outra. Então o pianista se vê obrigado a adaptar-se e a conseguir diferentes sonoridades; a ora tocar o solo, ora o acompanhamento; a buscar diferentes cores em função do equilíbrio sonoro. Dessa forma, acaba encontrando o lugar do piano no meio dos outros instrumentos.

A prática de conjunto não apenas abre seus horizontes como o torna mais responsável e versátil. Capaz de atuar em diferentes situações, ele encontra mais facilmente condições de trabalho; idealizando menos o momento do "concerto", lidando com situações menos pré-determinadas ele amplia o espaço da música na sua vida e ganha autonomia. (BARROS, 1998, p. 50-52)

Ao analisarmos a grade curricular de ambos os semestres de 2013 e do primeiro semestre de 2014, observamos que, dentre as matérias eletivas ofertadas nesse período, a leitura à primeira vista só consta no segundo semestre de 2013. Acreditamos que tal situação se deva ao fato da instituição não contar com um profissional efetivo que desenvolva a prática de leitura à primeira vista, dificultando assim o acesso dos alunos ao desenvolvimento desta que é a principal habilidade do pianista colaborador e uma importante ferramenta de trabalho para os músicos em geral. 


\section{A Oficina}

Entre os meses de agosto e novembro de 2013 foi realizada, na Universidade Estadual de Santa Catarina, uma oficina de piano colaborativo que visou desenvolver as habilidades do pianista colaborador.

A oficina foi dividida em duas etapas, uma teórica e a outra prática. Tal divisão foi pensada para que os alunos tivessem o conhecimento da existência de bibliografia sobre o assunto, contribuindo para que a experiência adquirisse um caráter mais acadêmico. Na parte prática da oficina visamos ao desenvolvimento da leitura à primeira vista, e como material para tal prática usamos canções de câmara brasileiras, árias italianas e Lieder, uma vez que o pianista colaborador atua frequentemente acompanhando cantores em ensaios, aulas ou master classes. Outro ponto trabalhado foi a visualização ampliada da partitura, ou seja, a visualização simultânea da parte do piano e do cantor e/ou instrumentista. Além das peças, utilizamos ainda uma seleção de trechos para piano em clave de Dó e clave de Fá, específico para o treinamento da leitura e transposição. O critério para a escolha dessas obras variou de acordo com o desempenho de cada aluno, mas mantivemos as escolhas baseando-nos na simulação de uma situação real na prática colaborativa, levando em consideração o nível do cantor e/ou instrumentista com os quais colaboraram. É importante ressaltar que todas as obras eram desconhecidas dos participantes.

Para que pudéssemos realizar uma comparação do desenvolvimento dos pianistas durante o período da oficina, fizemos registros em vídeo e relatórios descritivos desde os primeiros encontros. Nas últimas aulas houve a participação de três cantores (duas sopranos e um contratenor, com idades entre 20 e 34 anos), para que os alunos colocassem em prática os tópicos trabalhados em aula. Ao final da oficina foi aplicado um questionário para que deixassem registradas suas impressões em relação ao trabalho desenvolvido.

\section{Os Alunos}

Para obter uma amostragem diversificada, optamos por escolher pianistas com diferenças de idade, gênero e experiência musical. Todos declararam possuir pouca ou nenhuma experiência com a prática colaborativa, com exceção do aluno 4 que toca flauta transversal e faz parte de um grupo estável de música de câmara. Sendo assim, os alunos que fizeram parte da pesquisa são:

\begin{tabular}{|l|l|l|l|}
\hline Aluno & Sexo & Idade & Fase \\
\hline 1 & Masculino & 23 & 2 \\
\hline 2 & Masculino & 20 & 4 \\
\hline 3 & Feminino & 19 & 4 \\
\hline 4 & Feminino & 22 & 6 \\
\hline 5 & Masculino & 19 & 4 \\
\hline
\end{tabular}


No início da oficina notamos que nem todos os alunos estavam conscientes da importância dos assuntos e das atividades propostas. Como a prática colaborativa era um tema em relação ao qual não possuíam referências anteriores, precisamos de algumas aulas para ganhar a confiança do grupo. $O$ aluno 1 foi um dos que levaram mais tempo para demonstrar reconhecimento e receptividade em relação ao trabalho que estava sendo proposto.

A habilidade mais trabalhada na oficina foi a leitura à primeira vista. Desenvolver essa habilidade é uma tarefa árdua e não raramente um obstáculo para boa parte dos músicos. Segundo Pace $(1999$, p.1) apud Risarto (2010), ler à primeira vista ao piano, se define como a habilidade de poder ler e executar obras musicais desconhecidas sem praticar antecipadamente.

Por se tratar de uma prática incomum para esses alunos sugerimos que eles seguissem um roteiro durante o período de visualização da partitura e no momento da execução da leitura à primeira vista: 1) Verificar tonalidade e textura musical (polifônico, melódico); 2) Fixar uma pulsação rítmica internamente, baseado na fórmula de compasso apresentada e, mantê-la rigorosamente mesmo que o andamento seja mais lento; 3) Antecipar o olhar pelo menos um tempo a frente do que se está tocando; 4) Evitar olhar constantemente para o teclado; 5) Pensar harmonicamente em como as frases e o acompanhamento se desenrolam; 6) Tocar as notas com as dinâmicas e as articulações sugeridas pela partitura; 7) Se possível, construir as frases musicalmente, quer dizer, pensar no fraseado de cada trecho, ao invés de pensar em cada compasso; 8) A dinâmica precisa ser observada pois a tendência na leitura à primeira vista é sempre tocar $f f$; 9) Buscar fluência musical; 10) Não resolver os ornamentos na primeira leitura e, o mais importante de tudo, ter calma e tranquilidade, afinal todos nós conhecemos as notas musicais.

\section{Resultados}

A seguir faremos um breve relato do desempenho de cada um dos alunos participantes.

ALUNO 1: Segundo o próprio aluno relatou no questionário, sua experiência com a prática colaborativa e a sua leitura à primeira vista eram mínimas. Durante a execução da leitura à primeira vista pude observar que o aluno apresentava problemas rítmicos, harmônicos e dificuldade com a topografia do teclado. Uma de suas maiores dificuldades, que pude observar no momento da execução, foi a necessidade de olhar constantemente para o teclado. Esta atitude, segundo ele declarou no questionário, estava relacionada à ansiedade. Uma das peças designadas para esse aluno foi um trecho da ária da ópera Don Giovanni Vedrai carino - Mozart, que apresentava um padrão de notas duplas na mão direita e diversos trinados. 


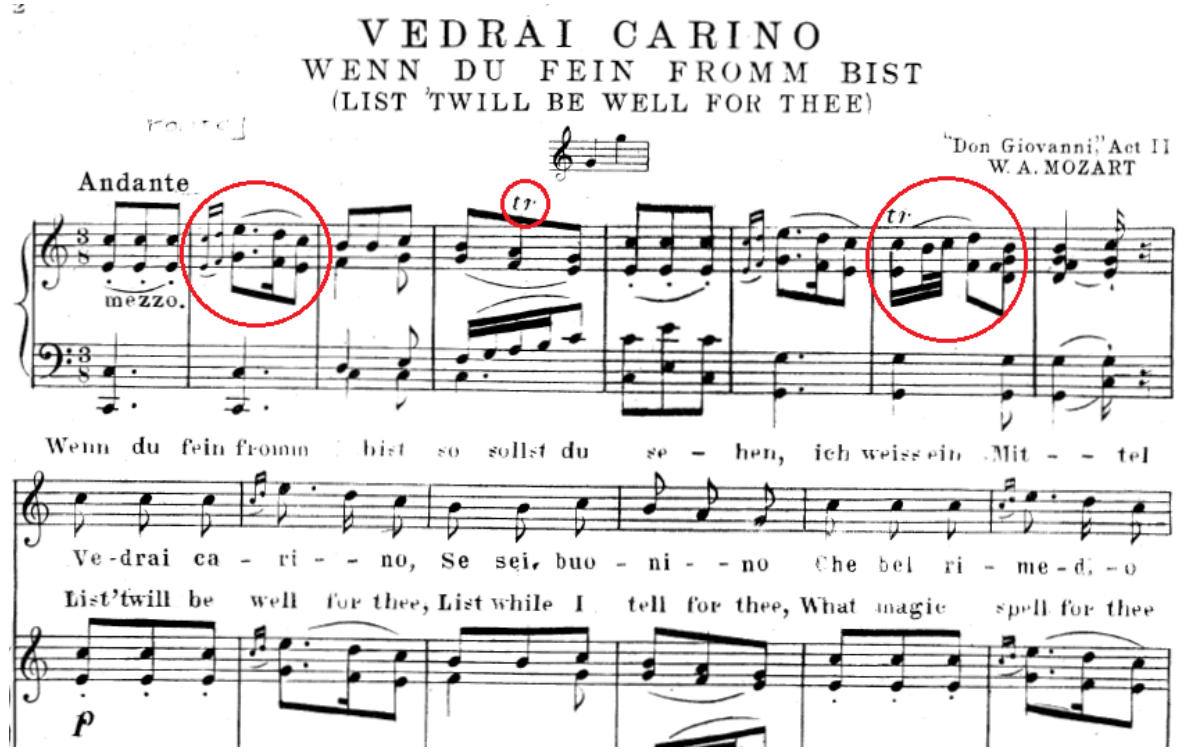

Fonte: Edited by H. E. Krehbie

Assim como os demais alunos, durante a master class realizada ao final da oficina com o professor Ms. John de Castro ${ }^{10}$, o aluno 1 participou do aquecimento dos cantores e executou a peça "Caro Laccio - F. Gasparini" com uma cantora, alcançando um resultado bastante satisfatório.

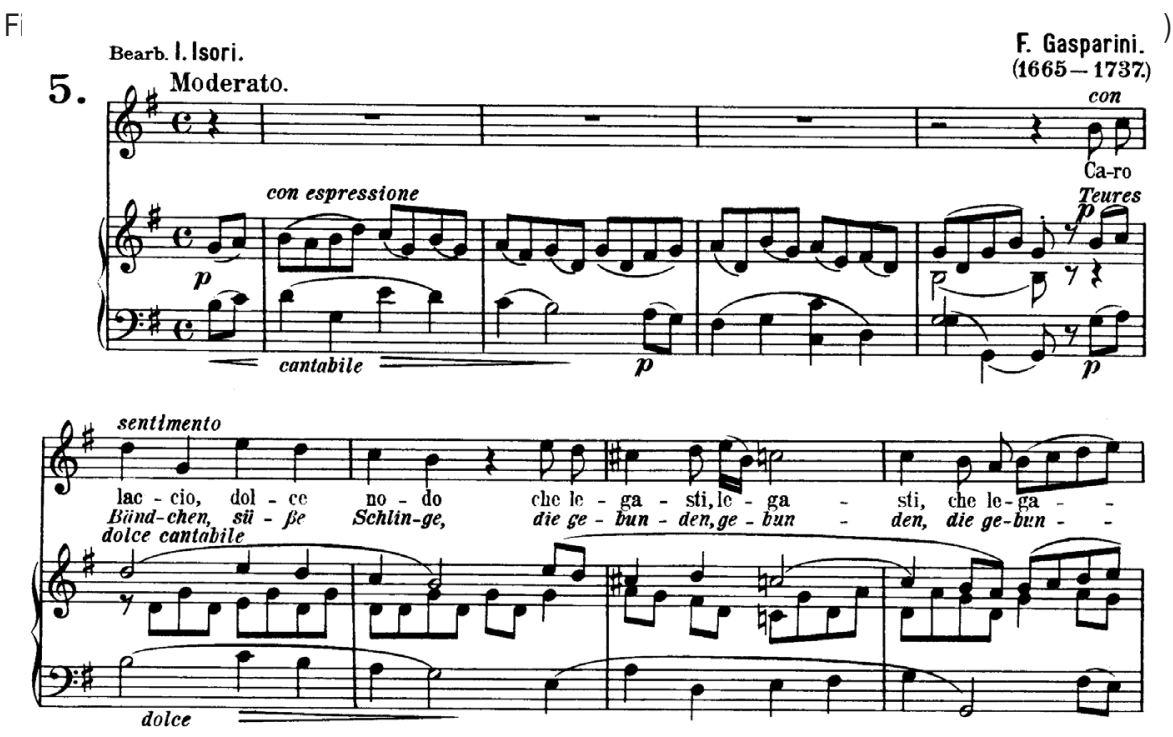

Fonte: Universal Edition wien Zurich London.

No registro em vídeo feito ao final da oficina, pudemos observar que houve

10 Professor da classe de bacharelado em canto no curso de Música na Universidade Estadual de Maringá (UEM), no Estado do Paraná. 
por parte do aluno 1 um considerável avanço no processo de leitura e a diminuição da quantidade de vezes que olhava para o teclado enquanto tocava.

ALUNO 2: Desde o primeiro encontro percebi o interesse desse aluno em aprender e a desenvolver as técnicas de leitura à primeira vista. Sempre procurava-me fora dos horários da oficina para esclarecer dúvidas e pedir sugestões de como resolver determinadas situações. No entanto, nos momentos de exposição pública, geralmente apresentava um baixo desempenho na performance. O grau de dificuldade das peças escolhidas para ele era menor em relação à dos seus colegas. Peças como Canção Nômade, de Waldemar Henrique e Little Minuet, de C.P.E. Bach foram algumas das obras que the foram designadas. Durante a execução de Canção Nômade, por exemplo, esqueceu das alterações e o andamento foi demasiadamente lento. Houve um problema rítmico, o grupo de semicolcheias executado em alguns momentos como e em outros como aluno não observou a anotação da partitura m.e (mão esquerda) que aparece logo após a sequência de semicolcheias e tentou realizar as notas com a mão direita. Houve uma tentativa de improvisação mas, sem sucesso.

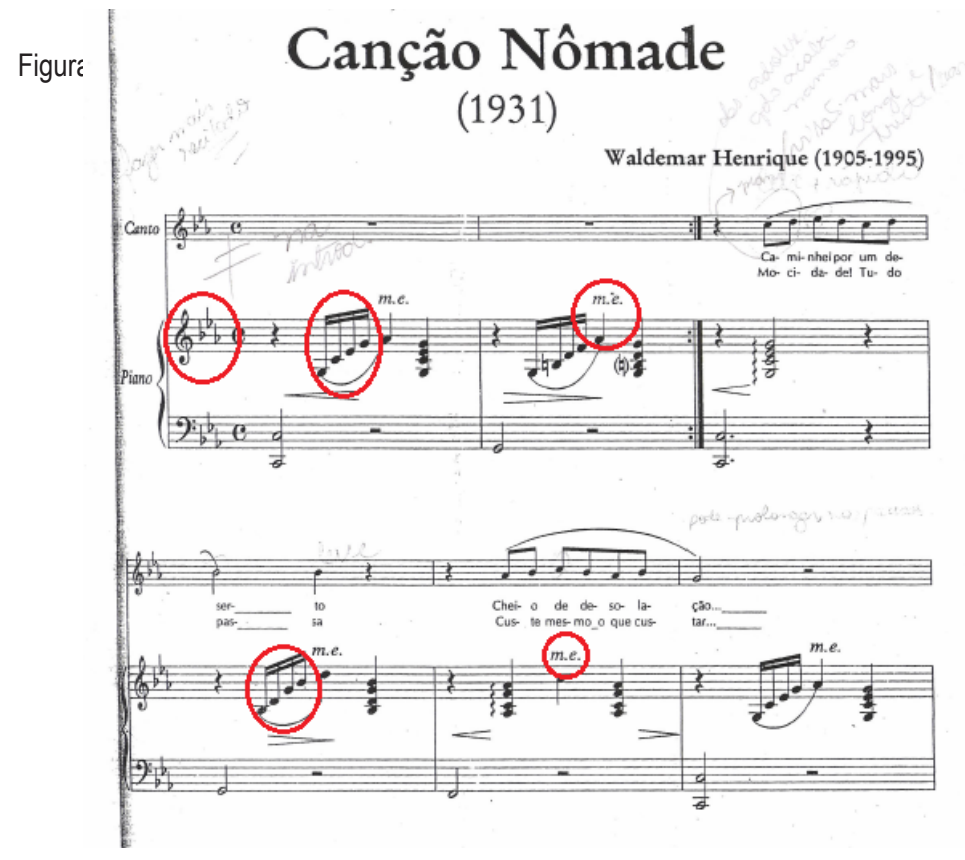

Fonte: Editada pela Fundação Carlos Gomes (Belém-Pará)

Quando houve a participação dos cantores nas aulas o aluno 2 tentava controlar a ansiedade, o que era praticamente impossível. Devido ao seu nervosismo, ele pediu para não participar da master class, que seria realizada no dia seguinte. Após a aula (antes da master), esta pesquisadora conversou com ele em particular, 
a fim de ajudá-lo, motivando-o à participar da master class. O resultado foi surpreendentemente positivo e no momento da execução, mesmo nervoso, superou-se e conseguiu executar a peça. A obra designada foi "Lascia ch'io Pianga - Händel". Pude observar que, no momento da execução preocupou-se não somente em acertar as notas, mas em realizar todo o fraseado da música, tanto no momento em que acompanhava a cantora quanto nos momentos de solo.

Figura 3: Trecho da obra "Lascia ch'io Pianga - Händel" executada pelo aluno 2 na master class. (compasso 43 ao 54)

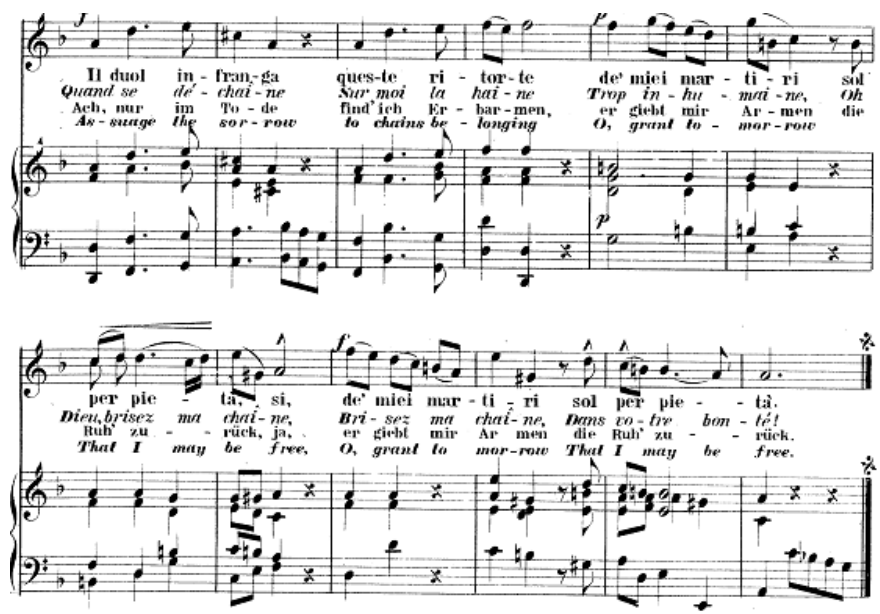

Fonte: G. Schirmer.

ALUNO 3: Demonstrou interesse pela prática colaborativa desde o primeiro momento. Sua experiência em relação a essa prática, segundo sua resposta no questionário, era pouca e sua leitura à primeira vista muito fraca. Ao executar a leitura, oscilações de ritmo e de andamento dificultavam a compreensão da obra. Outro agravante no processo de leitura à primeira vista foi a falta de familiaridade com a topografia do teclado, pois este aluno desviava constantemente o olhar da partitura ao teclado e vice-versa. Uma das peças designadas a este aluno foi a ária "Sebben Crudele - A. Caldara".

Figura 4: Trecho da obra "Sebben Crudele - A. Caldara" executado pelo aluno 3 na master class (comp. 1 ao 9)
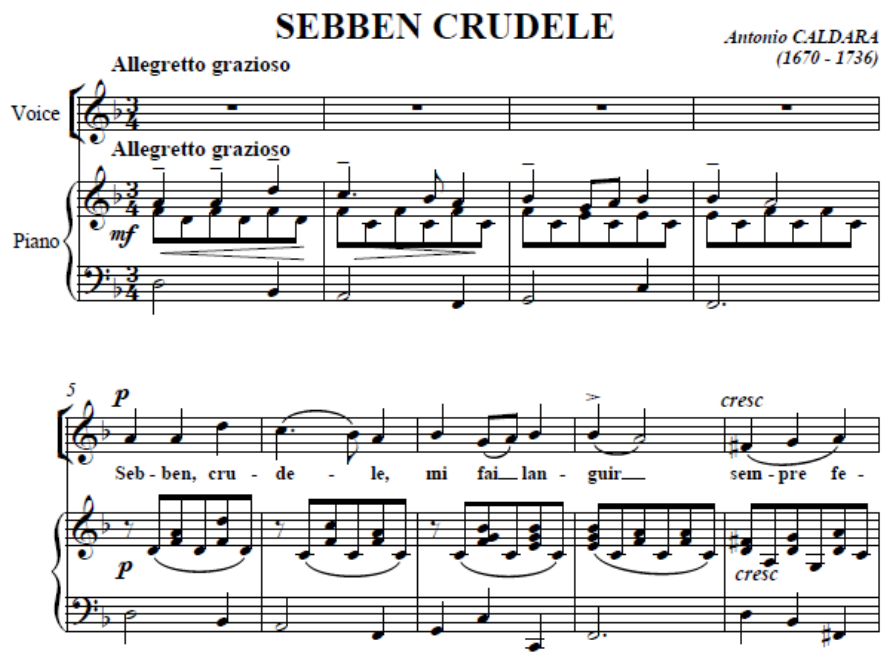

Fonte: Edition Lendic 
No momento da master class, este aluno pediu para participar apenas do aquecimento vocal. Ao ser questionado sobre o que mais lhe influenciou no desempenho durante a leitura à primeira vista esse aluno respondeu que foi o nervosismo por não conhecer a obra e também a falta de concentração. No encerramento da oficina executou uma leitura à primeira vista solo e outra a 4 mãos. $O$ resultado, em comparação com as experiências anteriores, foi muito satisfatório.

ALUNO 4: Desde o primeiro encontro pude observar que, de todos do grupo, este aluno era o que possuía mais experiência. Mostrou-se sempre interessado na prática colaborativa e foi o que mais questionou sobre as habilidades do pianista colaborador e como resolver problemas nas diversas situações a ele apresentadas. No entanto, seu conhecimento sobre o trabalho vocal com cantores era limitado, praticamente semelhante ao de seus colegas. Sua leitura à primeira vista era bastante desenvolvida mas, ao trabalhar uma peça a quatro mãos apresentou alguns problemas rítmicos, que resultaram em desencontros no momento da execução. Uma das poucas dificuldades enfrentadas por esse aluno foi a leitura de grade orquestral. Assim como para os demais, o processo de leitura em diversas pautas e com claves distintas não atingiu o resultado esperado.

Figura 5: Trecho da grade orquestral do Concerto in D para violino de W. A. Mozart (comp. 1 ao 6)

Mozart

Concerto No. 4

in D for Violin

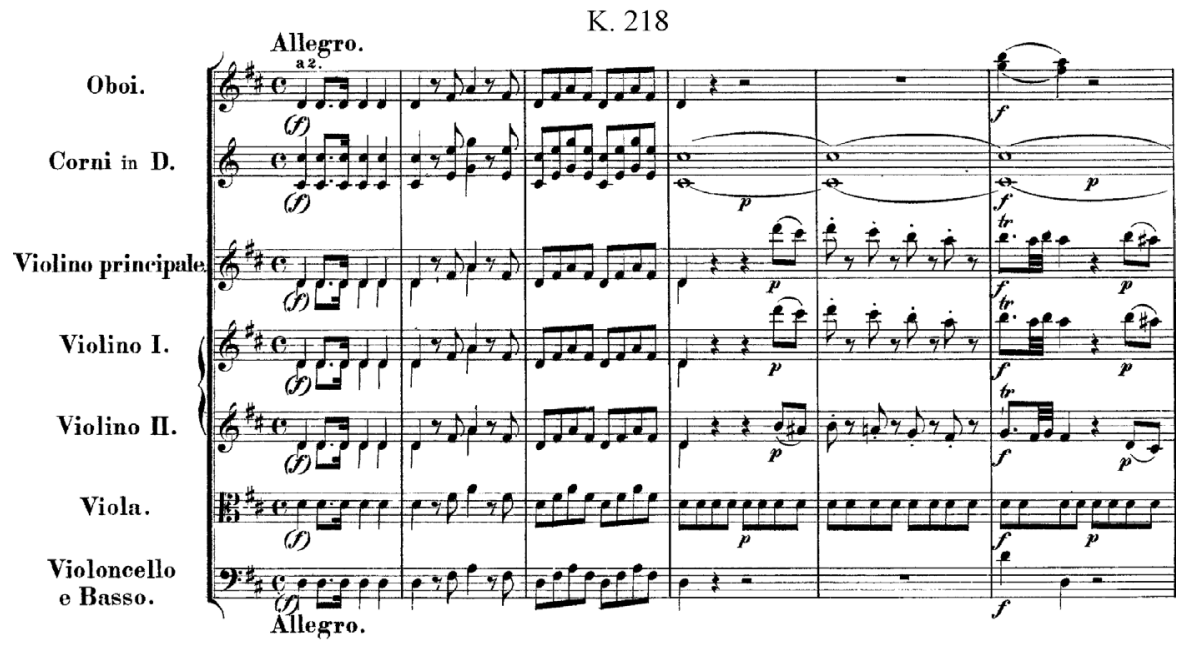

Fonte: Public Domain. Disponivel em http://petrucci.mus.auth.gr/imglnks/usimg/e/e5/IMSLP00872-Mozart_-_Violin_Concerto_No.4_ in_D_K.218.pdf

Devido à sua habilidade com a leitura à primeira vista, sugerimos para ele peças mais complexas (com saltos, notas duplas em intervalos diversos) do que as do restante do grupo. 
Figura 6: Trecho da obra Fischerweise - Schubert executado pelo aluno 4 (comp. 21 ao 30)

(191) 3

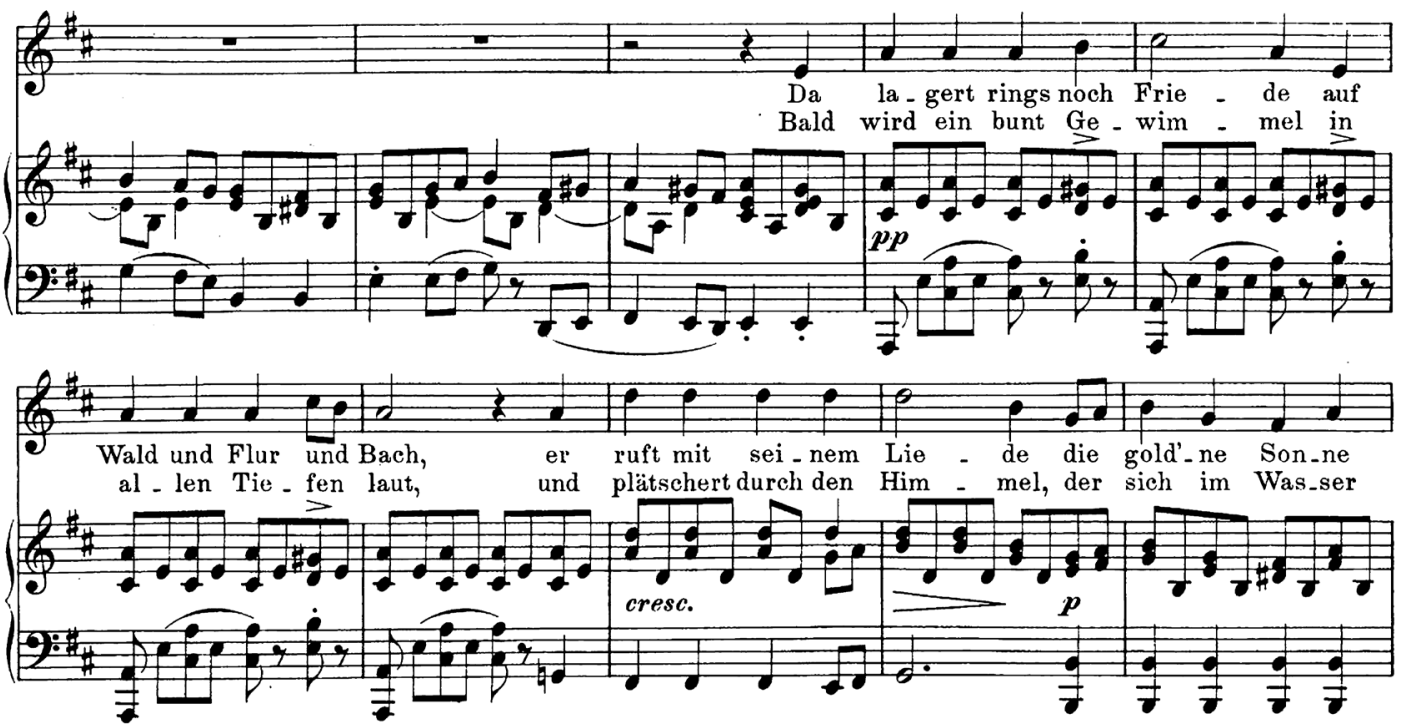

Fonte: Schubert's Werke.

Em todos os momentos da oficina, na master class e durante as gravações o aluno 4 apresentou um desempenho satisfatório, conseguindo manter a concentração e o equilíbrio emocional. Certamente sua experiência musical prévia contribuiu para esse resultado.

ALUNO 5: Foi um pouco dispersivo nas primeiras aulas, mas, após entrar em contato com o repertório camerístico brasileiro, passou a demonstrar interesse em estudar e participar mais da oficina. Embora possuísse um ouvido razoavelmente desenvolvido para a improvisação, a leitura demandava uma atenção especial. De todos os alunos era um dos mais comunicativos. Uma das obras designadas a ele foi Uirapurú -Waldemar Henrique. Nessa etapa ainda inicial da oficina ele apresentou problemas rítmicos e de localização das notas no teclado.

Figura 7: Trecho da obra Uirapurú de Waldemar Henrique executado pelo aluno 5 (comp. 1 ao 9)

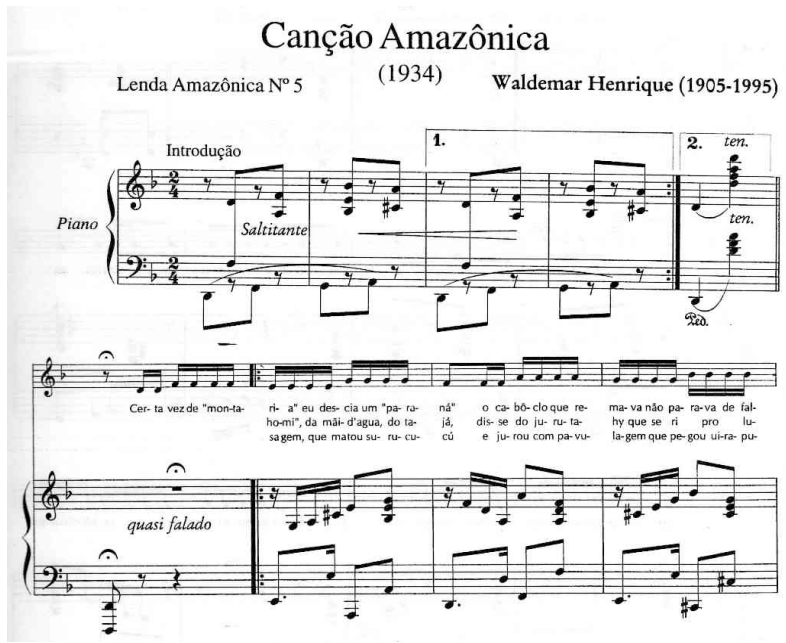

Fonte: Editada pela Fundação Carlos Gomes (Belém-Pará) 
Porém, à medida que o trabalho avançou obteve uma melhora significativa no seu desempenho. Na master class participou do aquecimento e executou a peça "Foi Bôto Sinhá! de Waldemar Henrique. Durante sua performance, o professor achou necessário transpor a peça pois a tonalidade não estava confortável para a cantora, elevando 1 tom da tonalidade original, o que esse aluno realizou perfeitamente e de imediato.

Figura 8: Trecho da obra Foi Bôto, Sinhá! de Waldemar Henrique executado pelo aluno 5 (comp. 1 ao 8)

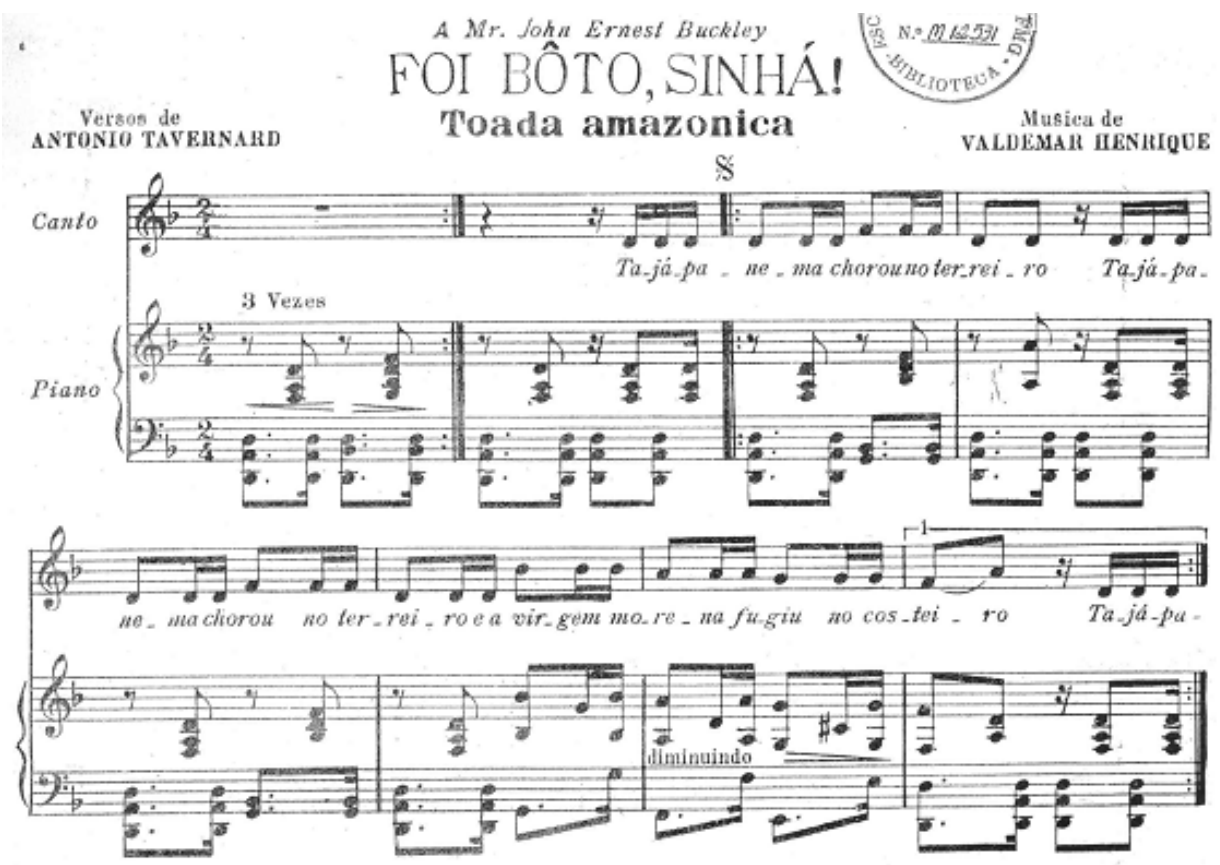

Fonte: Copyright by Mangione S.A. Sucessora de E. S. Mangione - São Paulo - Rio de Janeiro - Brasil. Disponível na Biblioteca da UFMG.

No encerramento da oficina realizou a obra a ele designada sem maiores dificuldades. Embora seu nível musical e pianístico fosse comparável ao dos alunos 1, 2 e 3 (conforme observamos, por conta de sua maior experiência musical, o aluno 4 se destacava dos demais), sua personalidade naturalmente comunicativa e sua atitude descontraída constituíram uma vantagem em relação aos colegas.

Após 6 meses do término da oficina nos interessamos em saber se a oficina trouxe para os alunos algum tipo de crescimento e se eles adotaram alguma das rotinas de estudo trabalhadas no grupo. Sendo assim, decidimos fazer uma entrevista com cada um deles a fim de sabermos de que maneira a prática colaborativa tornou-se presente em suas vidas.

Para esses alunos (com exceção ao aluno 2 que não faz mais parte do curso de música da universidade e com o qual não conseguimos estabelecer contato) a resposta em relação à oficina e à prática colaborativa foram positivas. Segundo o aluno 1 "... A oficina para mim, foi uma experiência de como é realmente o mercado lá fora e, foi assim, um ponta pé inicial..." . Com o aluno 3 a concentração e o medo eram fatores relevantes e após a oficina, segundo ele disse "... Ainda fico com medo, mas estou enfrentando mais, acho que tenho outra visão..." Para o aluno 4 a oficina 
trouxe mais segurança para a realização da prática “... tive coragem de aceitar acompanhar alguém, antes, mesmo que eu achasse que a peça não fosse tão difícil e que eu pudesse ter uma capacidade de desenvolvimento da peça em um curto período de tempo eu não tinha coragem, é muita responsabilidade". Já para o aluno 5, houve uma contribuição com o preparo do repertório solo "...na oficina eu li bastante coisa ai esse semestre quando fui pegar minhas peças eu tive muito mais facilidade de ler e resolver problemas..." Esses foram alguns dos pontos que, segundo eles, foram adquiridos com a oficina colaborativa. Todos estão envolvidos, de alguma maneira, com a prática colaborativa.

\section{Considerações}

Ao realizarmos a oficina, observamos que o desempenho dos pianistas colaboradores depende tanto da técnica pianística como da experiência musical prévia; mas também entram em jogo outros fatores importantes, tais como a concentração e o controle emocional durante a execução da leitura à primeira vista. No decorrer da oficina, o nível de autoconfiança dos alunos aumentou, sendo decisivo para um bom desempenho no momento da realização da master class realizada pelo professor e cantor Ms. John de Castro e no registro final da leitura à primeira vista. A oficina demonstrou que, com um trabalho direcionado e a ênfase na prática da leitura à primeira vista, a prática colaborativa pode se tornar uma realidade acessível a um grande número de estudantes de piano no meio acadêmico. 


\section{Referências}

\section{Livros}

ADLER, Kurt. The Art of Accompanying and Coaching. Editora University of Minnesota, Minnesota,1965.

KATZ, Martin. The Complete Collaborator: The Pianist as Partner. Oxford: Oxford University Press, 2009.

\section{Dissertações}

BARROS, G. S. - O Pianista Brasileiro: Do "Mito" do Virtuose à Realidade do Intérprete. Dissertação de Mestrado PPGM/UNIRIO, Rio de Janeiro, 1998.

COSTA, J.F. - Leitura à primeira vista na formação do pianista colaborador a partir de uma abordagem qualitativa. Dissertação de Mestrado CPG/IA/UNICAMP, Campinas 2011.

MARDEGAN, Flavia - Aprendizagem nos locais de trabalho: um estudo a partir das narrativas de profissionais que atuam como consultores comerciais na área de móveis planejados. 2011. 156f. Dissertação (Mestrado em Administração de Empresas) - Universidade Presbiteriana Mackenzie, São Paulo. 2011.

MONTENEGRO, G. F. C. - Os modos de ser e agir do pianista colaborador: um estudo de entrevistas com profissionais do centro de educação profissional - escola de música de Brasilia. Dissertação de Mestrado PPGM/UnB, BRASILIA, 2013.

MUNDIM, A.A. - PIANISTA COLABORADOR: A formação e atuação performática voltada para o acompanhamento de Flauta Transversal. Dissertação de Mestrado PPGM/UFMG, Belo Horizonte 2009;

MUNIZ, F.R.S - O Pianista Camerista, Correpetidor e Colaborador: As Habilidades nos Diversos Campos de Atuação. Dissertação de Mestrado PPGM/UFG, Goiânia 2010.

RISARTO, M. E. F. - A leitura à primeira vista e o ensino do piano. Dissertação de Mestrado UNESP, São Paulo 2010.

\section{Trabalhos de Conclusão de Curso}

UTRABO, M. - Perfil profissional dos egressos do bacharelado em música - opção piano - da UDESC (2002 a 2012). Trabalho de conclusão de curso, UDESC, Florianópolis, 2012.

UNGLAUB, A. R.; - Um olhar reflexivo sobre a leitura musical à primeira vista realizada por pianistas. Udesc, 2006

\section{Entrevistas}

RISARTO, Maria Elisa Ferreira. Entrevista editada no 1 com o Prof. Mestre Achille Picchi, realizada no dia 16 de outubro de 2008, na Escola Municipal de Música, gravada em MD . Entrevista editada no 17 com o Prof. Dr. Nahim Marun, realizada no dia 7 de julho de 2008 em sua residência em São Paulo, gravada em MD e editada pela mestranda.

Entrevista editada no 20 com o Prof. Dr. Ricardo Ballestero, realizada no dia 08 de abril de 2008 em sua residência em São Paulo, gravada em MD. 